\title{
UJI EFEKTIVITAS EKSTRAK BUAH ANGGUR HIJAU (VITIS VINIVERA L) TERHADAP DAYA HAMBAT LAJU PERTUMBUHAN BAKTERI STREPTOCOCCUS MUTANS DAN LACTOBACILLUS ACIDOPHILUS
}

\author{
BUSMAN, EDRIZAL, DWI WIDYA PANGGIH UTAMI
}

Universitas Baiturrahmah

Abstract: Streptococcus mutans and lactobacillus are acid-producers of carbohydrates that can be fermented and create the risk for cavity. Green grapes (Vitis vinifera L) is one of the fruit variety that contains the phytochemical from polyphenols class which functions as an inhibitors of glucosylation on plaque formation so that it was used as an antibacterial alternative in caries prevention. The purpose of this research was to determine the effectiveness of green grapes antibacterial towards Streptococcus mutans and lactobacillus acidophilus. The research design that used in this study was a laboratory experimental (Invitro).This research was conducted in Microbiology Laboratory of Andalas University, Padang City and the maceration was conducted in chemistry laboratoryKopertis region X (West Sumatra, Riau, Jambi, Riau Islands) Padang City, then the maceration is done in the Microbiology Laboratory of Andalas University Padang City on July 2019 until finished. The Samples on this research were the colonies of Streptococcus mutans bacteria and Lactobacillus acidophilus which obtained from the Laboratory of Andalas University, Padang city and Gajah Mada University and then they were bred at the Microbiology Laboratory of Andalas University Padang city with 4 treatments done and repeated as well 6 times so that the number of the samples were 24 treatments with the precentage of concentration $12.5 \%, 25 \%, 50 \%$, and $100 \%$ by used one way anova test. The results of the research showed the obtained number of sig $0.000<0.05$, it means that Ha received or it found the effectiveness of green grapes extracts (Vitis vinifera L) towards the inhibition capacity of Streptococcus mutants bacterium rate growth with best extract $50 \%$, and the number of sig 0.244>0.05, it means $\mathrm{Ha}$ was rejected or did not found the effectiveness of green grapes extracts(Vitis vinifera L) towards the inhibition of Lactobacillus Acidophilus rate growth.

Keywords: Green grapes extract (Vitis vinifera L), Streptococcus mutans and Lactobacillus acidophilus

\begin{abstract}
Abstrak: Streptococcus mutans dan Lactobacilli adalah penghasil asam dari karbohidrat yang dapat diragikan dan menciptakan risiko untuk gigi berlubang, anggur hijau (Vitis vinifera L) merupakan salah satu jenis buah yang mengandung fitokimia golongan polifenol yang berfungsi sebagai penghambat glukosilasi pada proses pembentukan plak sehingga digunakan sebagai alternatif antibakteri dalam pencegahan karies. Tujuan penelitian ini adalah untuk mengetahui efektifitas antibakteri anggur hijau terhadap Streptococcus mutans dan lactobacillus acidophilus. Jenis penelitian yang digunakan adalah eksperimental laboratorium (invitro). Penelitian dilakukan diLaboratorium Mikrobiologi Universitas Andalas Kota Padangdan maserasi dilakukan di Laboratorium kimia kopertis wilayah X (Sumatera Barat, Riau, Jambi, Kepulauan Riau) Kota Padang pada Juli 2019 - selesai. Sampel pada penelitian ini adalah koloni bakteri Streptococcus mutans dan Lactobacillus acidophilus yang diperoleh dari Laboratorium Universitas Andalas Kota Padang dan Universitas Gadjah Mada serta dibiakkan di Laboratorium Mikrobiologi Universitas Andalas Kota Padang dengan 4 perlakuan dan diulang sebanyak 6 kali sehingga besar sampel menjadi 24 E-ISSN: 2657-0300 Lembaga Penelitian dan Penerbitan Hasil Penelitian Ensiklopedia $\quad 325$ P-ISSN: 2657-0319
\end{abstract}


perlakuan dengan konsentrasi 12,5\%, $25 \%, 50 \%$, dan $100 \%$ menggunakan uji one way anova. Hasil penelitian diperoleh nilai sig $0,000 \leq 0,05$, artinya Ha diterima atau terdapat efektifitas ekstrak buah anggur hijau (Vitis vinifera $L$ ) terhadap daya hambat laju pertumbuhan bakteri Streptococcus mutandengan ekstrak terbaik 50\% dan nilai sig $0,244>0,05$, artinya Ha ditolak atau tidak terdapat efektifitas ekstrak buah anggur hijau (Vitis vinifera L) terhadap daya hambat laju pertumbuhan bakteri Lactobacillus acidophilus.

Kata Kunci: Ekstrak buah anggur hijau (Vitis vinifera L), bakteri Streptococcus mutans dan Lactobacillusacidophilus

\section{A. Pendahulan}

Kesehatan mulut merupakan hal penting untuk kesehatan secara umum dan kualitas pada kehidupan seseorang (WHO, 2012 sit Widayati, 2014). Penyakit rongga mulut merupakan salah satu masalah kesehatan utama yang paling cepat menyebar dan perlu dilakukan penanganan segera. Salah satu penyakit rongga mulut yang paling banyak diderita oleh masyarakat di seluruh dunia, termasuk di Indonesia adalah karies pada gigi (Rosdiana dan Nasution, 2016).

Prevalensi karies gigi di Indonesia terjadi cukup tinggi. Menurut hasil dari Riset Kesehatan Dasar (Riskesdas) Nasional tahun 2007, prevalensi karies di Indonesia mencapai $72,1 \%$ dan skor DMF-T mencapai 4,8. Hal ini juga didukung dari Survei Kesehatan Rumah Tangga (SKRT) tahun 2009 yang menunjukkan bahwa penduduk Indonesia yang menderita karies gigi sebesar 73\% (Mardianto, 2016). Menurut data Riskesdas 2013, prevalensi karies masyarakat Sumatera Barat berdasarkan indeks DMF-T (Decay, Missing, Filling) adalah 4,7 (Sandi, dkk. 2015).

Karies gigi adalah suatu penyakit mengenai jaringan keras gigi, yaitu enamel, dentin dan sementum, berupa daerah yang membusuk pada gigi. Hal ini terjadi karena adanya proses secara bertahap melarutkan mineral permukaan gigi dan terus berkembang kebagian dalam gigi. Selain itu, karena aktivitas jasad renik dalam karbohidrat yang dapat diragikan. Proses ini ditandai dengan dimineralisasi jaringan keras dan diikuti kerusakan zat organiknya, sehingga dapat terjadi invasi bakteri lebih jauh ke bagian dalam gigi ( Kumala, 2006 sit Widayati, 2014).

Faktor etiologi terjadinya karies yaitu mikroorganisme plak, diet, waktu (Mustika, dkk, 2014), dan host atau tuan rumah. Komposisi mikroorganisme dalam plak berbeda-beda. Pada awal pembentukan plak, kokus gram positif merupakan jenis yang paling banyak dijumpai seperti Streptococcus mutans, Streptococcus sanguis, Streptococcus mitis dan Streptococcus salivarius serta Lactobaccilus (Fatmawati, 2011). Streptococcus mutans adalah bakteri karies gigi dengan jumlah yang relatif besar, sebagai pembentuk polisakarida ekstra selular yang stabil. Bakteri ini memiliki kemampuan berkoloni pada tingkat keasaman $(\mathrm{pH})$ permukaan gigi yang relatif rendah sehingga sangat berperan pada laju pembentukan karies gigi (Santoso, dkk. 2012 sit Mahmuda dan Atun, 2017).

Lactobacillus acidophilus adalah bakteri penyebab karies yang paling dominan diantara spesies Lactobacillus lainnya. Bakteri inimerupakan bakteri gram positif yang dapat tumbuh dalam keadaan anaerob dansering menjadi agen penyebab terjadinya lesi karies sekunder yang dapat mempercepat proses demineralisasi yang berperan dalam proses perkembangan dan kelanjutan dari karies (Utami dan Medawati, 2017). Dewasa ini semakin banyak alternatif pengobatan menggunakan bahan alami sebagai 
antimikroba, karena bahan alami ini mempunyai efek samping yang rendah, kurang toksis dan mempunyai sifat biodegrabilitas lebih tinggi jika dibandingkan dengan obat konvensional (Rahmawati, dkk. 2016). Oleh karena itu, diperlukan upaya untuk mengendalikan bakteri ini salah satunya dengan menggunakan bahan yang bersifat antibakteri.

Anggur merupakan tanaman buah berupa perdu merambat yang termasuk ke dalam keluarga Vitaceae (Tajudin, dkk. 2012).Tanaman anggur hijau bukan merupakan tanaman asli Indonesia.Dari berbagai sumber pustaka menyebutkan bahwa tanaman anggur hijau diduga berasal dari Meksiko Selatan, Amerika Tengah, dan benua Amerika yang beriklim tropis. Di Samarinda, banyak yang membudidayakan tanaman anggur hijau ini untuk berwirausaha atau pun penghias halaman rumah (Astria dan Ailmuddin, 2018) dan di Indonesia sentral anggur terdapat di Jawa Timur ( Kediri, Probolinggo, Pasuruan, Situbondo), Bali dan Kupang (NTT) (Budiyati, 2012).

Sebelumnya telah dilakukan penelitian oleh Cahyaningsih (2014) tentang pengaruh daya antibakteri jus anggur (Vitis vinifera $L$ ) dengan konsentrasi 12,5\%, 25\%, 50\% dan 100\% terhadap pertumbuhan Streptococcus mutans secara in vitro. Hasil penelitian ini adalah jus anggur memiliki pengaruh daya antibakteri terhadap pertumbuhan Streptococcus mutans, semakin besar konsentrasi semakin besar pula daya antibakteri dari jus anggur dengan konsentrasi optimal dalam menghambat pertumbuhan Streptococcus mutans adalah $100 \%$.

Rumusan Masalah :Bagaimana gambaran uji efektifitas ekstrak buah anggur hijau (Vitis vinifera L) terhadap daya hambat laju pertumbuhan bakteri Streptococcus Mutan dan Lactobacillus Acidophilus? Tujuan Penelitian : Untuk mengetahui efektifitas ekstrak buah anggur hijau (Vitis vinifera L) dengan berbagai konsentrasi terhadap pertumbuhan bakteri Streptococcus mutan dan Lactobacillus acidophilus.

\section{B. Metodologi Penelitian}

Jenis penelitian yang digunakan dalam penelitian ini adalah eksperimental laboratorium (invitro). Cara Kerja nya adalah sebagai berikut:

Maserasi Ekstrak Anggur Hijau (Vitis vinivera L):

1. Anggur hijau (Vitis vinivera $L$ ) sebanyak $2 \mathrm{Kg}$ dibersihkan, dicuci dengan air sampai bersih dan ditiriskan.

2. Selanjutnya, anggur hijau tersebut diiris tipis dan dikeringkan 1 hari dibawah sinar matahari lalu dihari berikutnya dikeringkan pada suhu kamar hingga kering.

3. Anggur hijau yang telah dikeringkan, setelah itu sampel dihancurkan dengan cara di blender hingga hancur.

4. Pembuatan ekstrak ini dengan cara maserasi, yaitu dengan merendam anggur hijau ke dalam tabung gelap 2,5 liter dan tuangkan etanol 96\% dengan menggunakan corong kaca.

5. Lalu aduk dan didiamkan selama 24 jam dalam suhu kamar.

6. Setelah 24 jam direndam, anggur hijau disaring dengan menggunakan corong kaca dan kertas saring whatman ke dalam tabung erlenmayer hingga ampasnya terpisah dan ditambahkan pelarut baru lalu didiamkan kembali selama 24 jam kemudian dilakukan penyaringan kembali.

7. Ekstrak anggur hijau dimasukkan ke dalam labu untuk dievaporasi (diuapkan) dengan vacuum rotary sampai diperoleh ekstrak etanol kental dari anggur hijau. Ekstrak yang diperoleh dijadikan larutan dengan konsentrasi 12,5\%, 25\%, 50\%, dan $100 \%$. 
Pembuatan Konsentrasi Ekstrak Anggur Hijau (Vitis Vinivera L). Pada penelitian sebelumnya yang dilakukan oleh Natarini pada tahun 2007 membahas tentang perbandingan efek antibakteri jus anggur merah (Vitis vinifera) pada berbagai konsentrasi $(12,5 \%, 25 \%, 50 \%$ dan $100 \%)$ terhadap Streptococcus mutans maka dalam penelitian ini akan digunakan pula konsentrasi yang sama yaitu 12,5\%, 25\%, 50\%, dan $100 \%$. Bahan yang digunakan sebagai pelarut ekstrak anggur hijau adalah DMSO. Berat zat terlarut (ekstrak) yang digunakan yaitu memakai rumus sebagai berikut (Chairns, 2008 sit Pratiwi, 2016) :

Pembuatan Konsentrasi Ekstrak Buah Anggur Hijau

\begin{tabular}{|c|c|c|}
\hline Ekstrak Buah Anggur Hijau (gr) & Volume Akhir (ml) & Konsentrasi \\
\hline 1,25 & 10 & $12,5 \%$ \\
\hline 2,5 & 10 & $25 \%$ \\
\hline 5 & 10 & $50 \%$ \\
\hline 10 & 10 & $100 \%$ \\
\hline
\end{tabular}

Pembuatan Konsentrasi Amoxcicilin. Amoxcicilin didapatkan dengan membeli kapsul $500 \mathrm{mg}$. Konsentrasi amoxcicilin yang digunakan dalam penelitian ini adalah 5\%. Pembuatan konsentrasi dilakukan dengan melarutkan 0,5 gr dalam $10 \mathrm{ml}$ DMSO.

Pembuatan Medium. Larutan MullerHanton Agar dan Agar Darah sebanyak 6,8 gr ke dalam $200 \mathrm{ml}$ aquadest steril dan aduk sampai rata dan dipanaskan sampai mendidih menggunakan hot plate (Heidoph MR 300, Germany).Lalu bahan ini disterilkan dengan autoclave suhu $121^{\circ} \mathrm{C}$ dan tekanan 1 atm selama 15 menit.Dinginkan sampai suhu $45^{\circ} \mathrm{C}$ (sebelum membeku) kemudian tuangkan ke dalam cawan petri steril sebanyak $15 \mathrm{ml}$ dan dibiarkan sampai beku.

Suspensi Bakteri Streptococcus Mutans dan Lactobacillus Acidophilus. Bakteri yang digunakan Streptococcus mutans yang diperoleh dari Laboratorium Universitas Andalas Kota Padang dan Lactobacillus acidophilus yang diperoleh dari Universitas Gadjah Mada. Mengambil 1 ose koloni biakan bakteri Streptococcus mutans dan Lactobacillus acidophilus, bakteri disuspensi di dalam tabung reaksi dengan larutan fisiologis ( $\mathrm{NaCL}$ 0,9\%) sebanyak $10 \mathrm{ml}$ kemudian di vortex.

Uji Efektivitas Antibakteri. Metode yang digunakan adalah difusi agar.Siapkan 16 cawan petri yang berisi medium Muller Hinton Agar dan Agar Darah menggunakan cotton bud steril yang ditekan pada dinding dalam tabung sampai tidak ada cairan yang menetas lagi. Kertas cakram dicelupkan kedalam ekstrak anggur hijau (Vitis vinivera L) dengan konsentrasi 12,5\%, 25\%, 50\%, dan 100\%. Lalu letakkan kertas cakram diatas medium yang terdapat biakan bakteri Streptococcus mutans dan Lactobacillus acidophilus. Kemudian ditekan dengan menggunakan pinset agar kertas cakram benar-benar menempel pada media. Setelah itu diinkubasi selama 24 jam didalam incubator dengan suhu $37^{\circ} \mathrm{C}$. Setelah 24 jam, amati zona hambat yang terbentuk untuk mengetahui seberapa besar zona hambat sampel dilakukan pengukuran zona inkubasi yaitu daerah jernih pada permukaan Muller HintonAgar dan Agar Darah disekitar kertas cakram menggunakan jangka sorong.

Tabel : Kategori daya hambat antibakteri menurut Davis and Stout. (Andayani, R. dkk.Cit Marsa dan Dharmawati).

\begin{tabular}{|c|c|}
\hline Diameter Zona Hambat & Kategori daya hambat antibakteri \\
\hline$>20 \mathrm{~mm}$ & Sangat Kuat \\
\hline $10-20 \mathrm{~mm}$ & Kuat \\
\hline $5-10 \mathrm{~mm}$ & Sedang \\
\hline \multicolumn{2}{|c|}{} \\
\hline \multicolumn{2}{|c|}{ E-ISSN: 2657-0300 } \\
\hline 28
\end{tabular}




\begin{tabular}{|r|r}
\hline$<5 \mathrm{~mm}$ & Tidak ada \\
\hline
\end{tabular}

Analisis Data Deskriptif. Data yang disajikan dalam bentuk Tabel kemudian dianalisa secara deskriptif untuk menunjukkan hasil pengukuran diameter hambatan dalam satuan millimeter.

Analisis Statistik. Data yang diperoleh akan dianalisa secara statistic dengan tingkat signifikan 5\% dengan menggunakan aplikasi SPSS Uji One Way ANOVA. Pengambilan kesimpulan adalah sebagai berikut, jika nilai signifikan lebih kecil dari 0,05 maka pengaruh variabel bebas dan variabel terkait terebut adalah signifikan atau bermakna (Priyanto, 2009 Sit Pratiwi, 2016).

\section{Hasil dan Pembahasan}

Berdasarkan penelitian yang telah dilakukan untuk melihat efektifitas antibakteri ekstrak buah anggur hijau (Vitis vinifera $L$ ) terhadap pertumbuhan bakteri Streptococcus mutan dan Lactobacillus acidophilus dengan menggunakan ekstrak $12,5 \%, 25 \%, 50 \%$, dan $100 \%$ diperoleh hasil sebagai berikut:

Tabel : Rerata diameter zona bening ekstrak buah anggur hijau (Vitis vinifera $L$ ) serta kontrol positif (+) dan kontrol negatif (-) pada pertumbuhan bakteri Streptococcus mutan dan Lactobacillus acidophilus.

\begin{tabular}{llcc}
\hline \multirow{2}{*}{ No } & \multirow{2}{*}{ Kelompok } & \multicolumn{2}{c}{ Rerata Diameter $(\mathbf{m m})$} \\
\cline { 2 - 4 } & & S. mutan & L. acidophilus \\
\hline 1 & $12,5 \%$ & 28.8 & 8.2 \\
\hline 2 & $25 \%$ & 39.3 & 9.6 \\
\hline 3 & $50 \%$ & 54.0 & 10.2 \\
\hline 4 & $100 \%$ & 54.5 & 10.8 \\
\hline 5 & Kontrol $(+)$ & 30 & 10 \\
\hline 6 & Kontrol $(-)$ & 10 & 7 \\
\hline
\end{tabular}

Pada Tabel 5 menunjukan bahwa pada ekstrak 12,5\% diperoleh rerata daya hambat pertumbuhan bakteri Streptococcus mutan adalah 28,8 mm, pada ekstrak $25 \%$ adalah $39,3 \mathrm{~mm}$, pada ekstrak $50 \%$ diperoleh rerata $54 \mathrm{~mm}$ dan pada ekstrak $100 \%$ rerata $54,5 \mathrm{~mm}$. Peningkatan rerata paling efektif terjadi pada pemberian ekstrak buah anggur hijau (Vitis vinifera L) 50\% yaitu 54,0 mm. Jumlah rerata pertumbuhan bakteri Lactobacillus acidophilus ekstrak $12,5 \%$ adalah $8,2 \mathrm{~mm}$, ekstrak $25 \%$ adalah 9,6 mm, ekstrak 50\%adalah 10,2 mm dan ekstrak $100 \%$ sebanyak 10,8 mm. Peningkatan rerata paling efektif terjadi pada pemberian ekstrak buah anggur hijau (Vitis vinifera L) $50 \%$ yaitu 10,2 mm. Pada bakteri Streptococcus mutan diperoleh rerata diameter kontrol positif yaitu $30 \mathrm{~mm}$ dan pada kontrol negatif yaitu $7 \mathrm{~mm}$. Pada bakteri Lactobacillus acidophilus diperoleh rerata diameter kontrol positif yaitu $10 \mathrm{~mm}$ dan pada kontrol negatif yaitu $7 \mathrm{~mm}$.

Berdasarkan penelitian diperoleh hasil pada ekstrak $12,5 \%$ diperoleh rerata daya hambat pertumbuhan bakteri Streptococcus mutan adalah $28,8 \mathrm{~mm}$, pada ekstrak $25 \%$ adalah $39,3 \mathrm{~mm}$, pada ekstrak $50 \%$ diperoleh rerata $54 \mathrm{~mm}$ dan pada ekstrak $100 \%$ rerata $54,5 \%$. Peningkatan rerata paling efektif terjadi pada pemberian ekstrak buah anggur hijau (Vitis vinifera L) 50\% yaitu 54,0 mm. Jumlah rerata pertumbuhan bakteri Lactobacillus acidophilus ekstrak 12,5\% adalah 8,2 mm, ekstrak 25\% adalah 9,6 mm, ekstrak 50\% adalah 10,2\% dan ekstrak 100\% sebanyak 10,8 mm.

Peningkatan rerata paling efektif terjadi pada pemberian ekstrak buah anggur hijau (Vitis vinifera L) $50 \%$ yaitu 10,2 $\mathrm{mm}$ dan terdapat efektifitas ekstrak buah anggur hijau (Vitis vinifera L) terhadap daya hambat laju pertumbuhan bakteri

\begin{tabular}{lll}
\hline E-ISSN: 2657-0300 & Lembaga Penelitian dan Penerbitan Hasil Penelitian Ensiklopedia & 329 \\
P-ISSN: 2657-0319 &
\end{tabular}


Streptococcus mutan dengan nilai sig 0,000 < 0,05 dimana ekstrak $100 \%$ merupakan nilai rerata paling tinggi dibandingkan dengan ekstrak lainnya dan Hipotesa 2 nilai sig $0,244>0,05$, artinya Ha ditolak atau tidak terdapat efektifitas ekstrak buah anggur hijau (Vitis vinifera L) terhadap daya hambat laju pertumbuhan bakteri Lactobacillus acidophilus.

Menurut Davis dan Stout (1971) mengatakan bahwa ketentuan kekuatan daya anti bakteri sebagai berikut : zona hambat $20 \mathrm{~mm}$ atau lebih termasuk kategori sangat kuat, zona hambat 10-20 mm termasuk kategori kuat, zona hambat 5-10 mm kategori sedang dan zona hambat $5 \mathrm{~mm}$ atau kurang termasuk kategori lemah. Dengan demikian maka zona hambat yang dibentuk oleh ekstrak buah anggur hijau terhadap bakteri Streptococcus mutan pada konsentrasi 12,5\%, 25\%, 50\% dan 100\% termasuk dalam kategori sangat kuat. Pada zona hambat yang dibentuk oleh ekstrak buah anggur hijau terhadap bakteri Lactobacillus acidophilus pada konsentrasi $12,5 \%$ dan $25 \%$ termasuk dalam kategori sedang sedangkan pada konsentrasi $50 \%$ dan $100 \%$ termasuk dalam kategori kuat.

Pertumbuhan bakteri Streptococcus mutan pada esktrak 50\% memiliki rerata daya hambat terbaik yaitu $54 \mathrm{~mm}$. Hal ini disebabkan karena peningkatan konsentrasi menyebabkan semakin besar kadar fitokemikal yang terkandung. Sesuai dengan pendapat yang menyatakan bahwa efektifitas suatu bahan bergantung pada banyak faktor seperti konsentrasi, suhu, dan waktu. Hal ini sesuai dengan teori bahwa penurunan jumlah koloni pada setiap konsentrasi ekstrak buah anggur merah disebabkan kemampuan ekstrak anggur merah dalam membunuh bakteri, semakin tinggi konsentrasi supernatan jus buah anggur merah maka semakin besar kemampuan sebagai antibakteri. Kemampuan supernatant jus buah anggur dalam menghambat bakteri Streptococcus mutans disebabkan karena buah anggur merah mengandung zat antibakteri. (Kim T, 2008).

Kemampuan anggur dalam menghambat pertumbuhan Streptococcus mutans sesuai dengan penelitian yang dilakukan oleh (Rikasari dan Whidia, 2007) yang menujukkan bahwa kandungan terdapat pada anggur mampu menekan pertumbuhan bakteri mulut penyebab karies dan penyakit periodontal. Kandungan antibakteri yang terdapat dalam anggur antara lain golongan polifenol (Resveratrol dan tannin), golongan Flavonoid (quarcentin, catechin, pectin, oecyantin) dan asam lemak yaitu oleic acid, oleanolic acid, oleanolic aldehyde, botulin, betulinic acid. (Rahmawati, dkk. 2016).

Berdasarkan hasil penelitian hipotesa kedua tidak terdapat efektifitas ekstrak buah anggur hijau (Vitis vinifera $L$ ) terhadap daya hambat laju pertumbuhan bakteri Lactobacillus acidophilus dengan nilai sig 0,258 >0,05. Hal ini menunjukan bahwa Lactobacillus acidophilus memiliki kemampuan dalam metabolisme karbohidrat dan juga memiliki kemampuan dalam $\mathrm{pH}$ yang sangat rendah. Selain itu, Lactobacillus acidophilus memiliki kemampuan dalam memproduksi polisakarida ekstraseluller (EPS), yang nantinya akan berperan dalam pembentukan matriks plak, walaupun perlekatannya pada gigi tidak sekuat yang dihasilkan Streptococcus mutans (Badet, dkk. 2008).

Lactobacillus acidophilus diketahui tahan terhadap $\mathrm{pH}$, garam empedu, asam lambung, suhu, dan antibakteri. Ketahanannya ini dikarenakan bakteri ini merupakan bakteri gram positif yang memiliki dinding sel tebal dengan ukuran 18-80 nm. Tebalnya tergantung pada peptidoglikan dan asam. Dinding sel bakteri menentukan 
bentuk dan berfungsi melindungi bagian dalam sel terhadap pemberian antibiotic atau bahan antibakteri dan kondisi lingkungan lainnya. Dinding sel terdiri dari beberapa lapisan untuk melindungi sitoplasma yang merupakan tempat berlangsungnya proses biokimia (Agustiani,dkk. 2017).

Rerata pada ekstrak $100 \%$ merupakan ekstrak dengan rerata tertinggi yaitu 54,5 mm dibandingkan dengan ekstrak lainya bahkan dengan rerata pada control positif yaitu $30 \mathrm{~mm}$ terhadap daya hambat pertumbuhan bakteri Streptococcus mutan, hal ini membuktikan bahwa ekstrak buah anggur hijau (Vitis vinifera L) lebih baik digunakan dari pada control positif dengan amoxicillin, hal tersebut disebabkan karena buah anggur hijau (Vitis vinifera L) merupakan salah satu jenis buah yang mengandung fitokimia golongan polifenol, flavonoid, dan asam lemak berfungsi sebagai penghambat glukosilasi pada proses pembentukan plak sehingga digunakan sebagai alternatif antibakteri dalam pencegahan karies (Cahyaningsih, 2014) dan dengan adanya antibacterial dan antivirus yang kuat dapat melindungi tubuh dari infeksi (Susanto, 2018).

\section{Penutup}

Berdasarkan hasil penelitian tentang efektivitas antibakteri ekstrak buah anggur hijau (Vitis vinifera L) terhadap pertumbuhan bakteriStreptococcus mutansdanLactobacillus acidophilusdiperoleh kesimpulan bahwa Ha diterima atau terdapat efektifitas ekstrak buah anggur hijau (Vitis vinifera $L$ ) terhadap daya hambat pertumbuhan bakteri_Streptococcus mutan_dengan peningkatan rerata paling efektif terjadi pada pemberian ekstrak buah anggur hijau (Vitis vinifera L) 50\% yaitu 54,0 $\mathrm{mm}$. Hasil selanjutnya yaitu bahwa Ho diterima atau tidak terdapat efektifitas ekstrak buah anggur hijau (Vitis vinifera L) terhadap daya hambat pertumbuhan bakteri Lactobacillus acidophilus dengan Peningkatan rerata paling efektif terjadi pada pemberian ekstrak buah anggur hijau (Vitis vinifera L) $50 \%$ yaitu 10,2 mm.

\section{Daftar Pustaka}

Agustiani, D. Kharisma, Y. dan Romadhona, N. 2017. Efek Antibakteri Ekstrak Air Buah Pepaya (Carica papaya L) Muda Terhadap Lactobacillus acidophilus.Bandung Meeting on Global Medicine and Health (BaMGMH). Vol. 01, No. 01.

Astria, LY., Bohari \& Alimuddin, 2018. Analisa Kadar Vitamin C Pada Buah Anggur Hijau (vitis vinifera) Dengan Variasi Lama Penyimpanan Pasca Panen.Jurnal Atomik, Vol. 03, No. 02, Hal. 68-72.

Badet, C \& Thebaud, N.B. 2008. Ecology of Lactobacilli in the Oral Cavity: A Review of Literature. Open Microbiol J. Vol. 2, Hal. 38-48.

Budiyati, E. 2012.Balai Penelitian Tanaman Jeruk dan Buah Subtropika Badan Penelitian dan Pengembangan Pertanian.

Cahyaningsih, R. 2014. Pengaruh Daya Antibakteri Jus Anggur (Vitis vinifera l.) Dengan Konsentrasi 12,5\%, 25\%, 50\% dan 100\% Terhadap Pertumbuhan Streptococcus mutans Secara In Vitro. Karya Tulis Ilmiah Strata 1, Fakultas Kedokteran Gigi, Universitas Muhammadiyah Surakarta.

Fatmawati, D.W.A. 2011.Gambaran Daya Hambat Minyak Kelapa Murni dan Minyak Kayu Putih dalam Menghambat Pertumbuhan Streptococcus Mutans. Stomatognatic (J.K.G Unej), Vol. 8, No. 3, Hal. 127-130. 
Kim. T, Silva. J.L, Jung. Y.S. 2008. Antibacterial Activity of Fresh and Processed Red Muscadine Juice And The Role Of There Polar Compounds O Escheria Coli. Mississipi. Journal Cmpilation.

Mahmudah, F.L. \& Atun, S. 2017. Uji Aktifitas Antibakteri Dari Ekstrak Etanol Temukunci (Boesenbergia pandurata) Terhadap Bakteri Streptococcus mutans.Jurnal Penelitian Saintek, Vol. 22, No. 1.

Mardianto, R.W.G. 2016. Gambaran Status Karies Gigi Anak Sekolah Dasar Kota Malang. Jurnal Preventia, Vol. 1, No 1.

Mustika, M.D., Carabelly, A.N. dan Cholil. 2014. Insidensi Karies Gigi Pada Anak Usia Prasekolah Di TK Merah Mandiangin Martapura Periode 2012-2013. Dentino (Jur. Ked.Gigi), Vol. 2, No 2, Hal.200-204.

Pratiwi, R.R, 2014. Uji Efektifitas Antibakteri Ekstrak Etanol Daun Mangga Bacang (Mangifera Foetida L) Terhadap Stapylococcus aureus Secara In vitro, Tanjungpura.

Rachmawati, D., Sumarno, Cahyani, A.W.N. 2016. Efek Antibakteri Supernatan Jus Anggur Merah Yang Diisolasi Dengan Kecepatan Sentrifugasi 12.000 Rpm Terhadap Pertumbuhan S. Mutans.Dental Journal. Vol. 03. No. 02.

Rosdiana, N. \& Nasution, A.I. 2016. Hubungan Biofilm Streptococcus Mutans Terhadap Resiko Terjadinya Karies Gigi .Rosdiana $N$ et al/J Syiah Kuala Dent Soc, Vol. 1, No. 1, Hal. 43 - 50.

Sandi, I.M, Bachtiar, H, dan Hidayati. 2015. Perbandingan Efektivitas Daya Hambat Dadih Dengan Yogurt Terhadap Pertumbuhan Bakteri Streptococcus mutan. Jurnal B-Dent, Vol. 2, No. 2, Hal. 88- 94.

Susanto, D.B. 2018. 256 Resep Jus Buah Dan Sayuran Jus Dahsyat Tumpas Penyakit Sehat dan Awet Muda. www.shiramedia.com.

Tajuddin, R, Suwastika, N \& Muslimin, 2012, 'Organogenesis Tanaman Anggur Hijau (Vitis vinifera) Pada Medium MS Dengan Penambahan IAA (indole acetid acid) dan Berbagai Konsentrasi BAP (benzil amino purin)', Jurnal Natural Science, Vol. 1, No. 1. Hal. 63.

Utami, S. 2013. Hubungan Antara Plak Gigi Dengan Tingkat Keparahan Karies Gigi Anak Usia Prasekolah. IDJ, Vol. 2, No. 2.

Widayati, N. 2014. Faktor Yang Berhubungan Dengan Karies Gigi Pada Anak Usia 46 Tahun. Jurnal Berkala Epidemiologi, Vol. 2, No. 2, Hal. 196-205. 